\title{
Type 2B von Willebrand Disease: A Matter of Plasma Plus Platelet Abnormality
}

\author{
Giancarlo Castaman, MD ${ }^{1}$ Augusto B. Federici, MD² \\ ${ }^{1}$ Center for Bleeding Disorders, Department of Heart and Vessels, \\ Careggi University Hospital, Firenze, Italy \\ 2 Department of Oncology and Hematology, University of Milan, \\ Hematology and Transfusion Medicine, L. Sacco University Hospital, \\ Milan, Italy \\ Address for correspondence Giancarlo Castaman, MD, Center for \\ Bleeding Disorders, Department of Heart and Vessels, Careggi \\ University Hospital, 50134 Firenze, Italy \\ (e-mail: castaman@aou-careggi.toscana.it).
}

Semin Thromb Hemost 2016;42:478-482.

\begin{abstract}
Keywords

- von Willebrand disease

- type $2 \mathrm{~B}$

- thrombocytopenia

- inherited bleeding disorders

- platelets

- platelet function disorders

Type 2B von Willebrand disease (VWD2B) is a rare, autosomal-dominant inherited bleeding disorder, characterized by an enhanced ristocetin-induced platelet aggregation in platelet-rich plasma and often with variable degree of thrombocytopenia and loss of high-molecular-weight multimers von Willebrand factor (VWF). All these phenomena are caused by a mutant VWF, normally synthesized and assembled by endothelial cells, but with heightened affinity binding to the platelet receptor glycoprotein Ib- $\alpha(G p l b-\alpha)$. When this abnormal VWF is released into the circulation and under specific clinical circumstances, in vivo platelet clumping is observed. Mutations, invariably clustered in exon 28 of the VWF gene encoding for the VWF A1 domain involved in VWF binding to Gplb- $\alpha$, are responsible for VWD2B phenotype. Clinical and laboratory phenotype appears strongly related to the type of VWF-causative mutations. However, recent evidences suggest that a true platelet defect is also present in this type, with several morphological and functional abnormalities being detected in a subset of VWD2B patients.
\end{abstract}

von Willebrand disease (VWD) is a common autosomal-dominant inherited bleeding disorder caused by quantitative or qualitative defects of von Willebrand factor (VWF), a multiadhesive protein which binds platelets to exposed subendothelium, participates in platelet aggregation and carries factor VIII in circulation. VWD is classified into six different types ( $\mathbf{-}$ Table $\mathbf{1}$ ). Type 1 and 3 VWD reflect the partial or complete quantitative deficiency of VWF, respectively, while four type 2 variant reflect different qualitative defects of $\mathrm{VWF}^{1}$ Type 2 displays a wide heterogeneity of functional abnormalities reflecting the location of the causative mutations in the VWF protein.

Among type 2 variants, VWD type $2 \mathrm{~B}$ (VWD2B) is unique because of its peculiar pathophysiology and laboratory phenotype. ${ }^{2}$ This was first shown by Ruggeri et al who identified a group of VWD patients, now classified as type VWD2B, with variable reduction of plasma VWF, but with in vitro ristocetin-induced platelet agglutination (RIPA) occurring at concentrations lower than those required for normal controls and other patients with VWD. ${ }^{3}$ Subsequently, a lack of high-molecular-weight (HMW) multimers of VWF in plasma was observed and attributed to a heightened interaction of the abnormal VWF with the physiological glycoprotein (Ib- $\alpha$; GpIb- $\alpha$ ) receptor on platelet membrane. ${ }^{4}$ Furthermore, increasing plasma concentration of this mutant protein by administering desmopressin (DDAVP) could induce a variable degree of thrombocytopenia, which was however, already present at baseline in a significant proportion of patients. ${ }^{5,6}$

VWD2B is a rare ( $3 \%$ of all VWD cases), usually highly penetrant autosomally inherited bleeding disorder caused by gain-of-function mutations in A1 domain of VWF. ${ }^{6}$ Around $50 \%$ of patients with this type exhibit mild-to-moderate thrombocytopenia, which can be unraveled or further aggravated by some clinical circumstances (e.g., surgery, infection, published online May 5, 2016
Issue Theme Controversies in Inherited Bleeding Disorders; Guest Editors: Antonio Coppola, MD, Massimo Franchini, MD, and Annarita Tagliaferri, MD.
Copyright $\odot 2016$ by Thieme Medical Publishers, Inc., 333 Seventh Avenue, New York, NY 10001, USA. Tel: +1(212) 584-4662.
DOI http://dx.doi.org/ 10.1055/s-0036-1579638. ISSN 0094-6176. 
Table 1 Classification of VWD

\begin{tabular}{|c|}
\hline Quantitative deficiency of VWF \\
\hline Type 1: Partial quantitative deficiency of VWF \\
\hline Type 3: Virtually complete deficiency of VWF \\
\hline Qualitative deficiency of VWF (variant VWD) \\
\hline Type 2: Qualitative deficiency of VWF \\
\hline $\begin{array}{l}\text { Type 2A: Qualitative variants with decreased } \\
\text { platelet-dependent function associated with the } \\
\text { absence of high- and intermediate-molecular-weight } \\
\text { VWF multimers }\end{array}$ \\
\hline $\begin{array}{l}\text { Type 2B: Qualitative variants with increased affinity } \\
\text { for platelet GPIb }\end{array}$ \\
\hline $\begin{array}{l}\text { Type 2M: Qualitative variants with decreased } \\
\text { platelet-dependent function not caused by the absence } \\
\text { of high-molecular-weight VWF multimers }\end{array}$ \\
\hline $\begin{array}{l}\text { Type } 2 \mathrm{~N} \text { : Qualitative variants with markedly decrease } \\
\text { affinity for factor VIII }\end{array}$ \\
\hline
\end{tabular}

Abbreviations: Gplb, glycoprotein Ib; VWD, von Willebrand disease; VWF, von Willebrand factor.

Source: Modified from Sadler et al. ${ }^{1}$

pregnancy), because of the increased release of the abnormal VWF by the endothelial cells. ${ }^{6}$

\section{Genetic Background and Heterogeneity of Laboratory Phenotypes}

Along with type 2A, VWD2B was the first type of VWD for which demonstration of specific causative VWF mutation has been provided. ${ }^{7,8}$ The identification of specific segments in the A1 domain responsible for the interaction with platelet GpIb- $\alpha$ receptor has led to investigating exon 28 of VWF gene, which codes for A1 domain. ${ }^{7,8}$ Indeed, several mutations, all clustered in exon 28 have been associated with VWD2B (-Table 2) (also see, http://www.ragtimedesign.com/vwf/ mutation/), for most of them expression experiments have clearly demonstrated the causative role of the amino acid change. Most VWD2B mutations are missense, of which R1306W, R1308C, V1316M, and R1341Q represent approximately 80 to $90 \%$ of the observed mutations. ${ }^{9}$ For some of these mutations, there is a clear relationship with loss of HMW multimers and chronic thrombocytopenia while it has been shown that P1266L mutation, previously reported as type New York/Malmoe VWD, ${ }^{10,11}$ is invariably not associated with loss of HMW multimers and thrombocytopenia. ${ }^{6}$

\section{How Type 2B VWF Influences Platelets}

Patients with some mutations (e.g., I1309V, V1316M) are particularly prone to develop thrombocytopenia at baseline or after triggering clinical situations, ${ }^{6}$ while in others it does not occur at all (e.g., P1266Q/L or 3923G $>$ T R1308L). Thrombocytopenia inversely correlates with the increase of circulating levels of conformational active form of type 2B VWF, which may also interact spontaneously with GpIb- $\alpha^{6}$
Table 2 Mutations identified in exon 28 of VWF gene associated with type 2B VWD phenotype

\begin{tabular}{|c|c|}
\hline Nucleotide change & Amino acid substitution \\
\hline $3797 \mathrm{C}>\mathrm{T}$ or $\mathrm{A}$ & P1266L/Q \\
\hline $3802 C>A$ or $G$ & $\mathrm{H} 1268 \mathrm{~N} / \mathrm{D}$ \\
\hline $3910 A>G$ & M1304V \\
\hline 3912insATG & M1304insM \\
\hline $3916 C>T$ & R1306W \\
\hline $3917 G>A$ & R1306Q \\
\hline $3917 G>T$ & R1306L \\
\hline $3922 C>T$ & R1308C \\
\hline $3923 G>C$ & R1308P \\
\hline $3925 A>G$ & I1309V \\
\hline $3929 \mathrm{C}>\mathrm{T}$ & S1310F \\
\hline $3939 G>C$ & W1313C \\
\hline $3940 \mathrm{G}>\mathrm{C}$ & V1314L \\
\hline $3941 \mathrm{~T}>\mathrm{A}$ & V1341D \\
\hline $3946 \mathrm{C}>\mathrm{A}$ & V1316M \\
\hline $4010 \mathrm{C}>\mathrm{T}$ & P1337L \\
\hline $4021 C>T$ & R1341W \\
\hline $4022 \mathrm{G}>\mathrm{A}$ or $\mathrm{C}$ or $\mathrm{T}$ & $\mathrm{R} 1341 \mathrm{Q} / \mathrm{P} / \mathrm{L}$ \\
\hline $4115 \mathrm{~T}>\mathrm{G}$ & $11372 S$ \\
\hline $4378 C>G$ & L1460V \\
\hline $4382 \mathrm{C}>\mathrm{A}$ or $\mathrm{T}$ & A1461D/V \\
\hline
\end{tabular}

Abbreviation: VWD, von Willebrand disease.

Apart from affecting the interaction with GPIb- $\alpha$, recent findings suggest that 2B VWF may also affect platelet production. In addition to platelet aggregates, in peripheral blood smears of VWD2B patients giant platelets may also be evident. ${ }^{6,12}$ of note, recently it has been shown that the disorder previously called Montreal platelet syndrome, characterized by thrombocytopenia with large platelets and bleeding symptoms, is indeed caused by the V1316M VWF mutation. ${ }^{13}$ Megakaryocytes from patients with VWD2B have an altered morphology and produce abnormal and fewer platelets than normal controls, suggesting that the continuous interaction with Gplb- $\alpha$ of abnormal VWF during megakaryocytes maturation influences the formation of platelets in these patients. ${ }^{14}$ Recently, in a murine model for VWD2B, which reproduces the phenotype observed in human patients with the disorder, Casari et al found that murine VWD2B platelets, again depending on the type of mutation, have a variably shorter circulatory survival than wild-type platelets, which could contribute to the lower platelet count in VWD2B mice. ${ }^{15}$ This underlines the role of VWF-type $2 \mathrm{~B}$ in inducing the formation of abnormal platelets with shortened lifespan in circulation. Importantly, further analysis revealed that VWF-type $2 \mathrm{~B}$ is exclusively present at the surface of platelets of thrombocytopenic VWD2B mice, suggesting that VWF binding to platelets is needed to induce thrombocytopenia. ${ }^{15}$ 
These VWF-platelet complexes are taken up efficiently by macrophages in the liver and spleen, thus accelerating their clearance. ${ }^{16,17}$ Interestingly, increase of circulating levels of conformational active form of $2 \mathrm{~B}$ VWF also promotes VWF binding by macrophages. Macrophage depletion leads to a two- to threefold increase of platelet counts in thrombocytopenic mice with type 2B V1316M mutation, characterized by the most severe thrombocytopenia. ${ }^{15}$ Furthermore, it was recently found that activation of VWF via exposure to shear stress, enhances macrophage uptake, thus contributing significantly to the clearance of VWF. ${ }^{17}$

Thus, thrombocytopenia in VWD2B appears to be the result of at least a combination of shortened survival of the abnormal platelets and of an accelerated clearance of the abnormal $\mathrm{VWF} /$ platelet complexes by macrophages in the liver and spleen. ${ }^{18}$ VWD2B appears to not only be a disorder of a plasma hemostatic protein, but also of platelets, suggesting that, in addition to VWF/factor VIII concentrates, transfusion of normal platelets may be justified in VWD2B patients with bleeding and worsening of their thrombocytopenia due to hemostatic stress situations. ${ }^{18}$

Furthermore, recent studies from the same group demonstrated that also platelet dysfunction is present in VWD2B. ${ }^{19}$ A dysregulated platelet signaling upon binding to GpIb- $\alpha$, which severely impairs platelet aggregation, secretion and platelet spreading was in fact demonstrated on the basis of a decreased activation of the platelet fibrinogen integrin receptor $\alpha \mathrm{IIb} \beta 3$ as a consequence of type $2 \mathrm{~B}$ VWF binding to GpIb- $\alpha$. This altered platelet function would of course add to increase the risk of bleeding carried by low VWF with loss of HMW multimers and thrombocytopenia. ${ }^{20}$

\section{Proteolysis and Clearance of Type 2B Von Willebrand Factor}

Loss of HMW multimers in VWD2B is due to increased ADAMTS13 (a disintegrin and metalloproteinase with a thrombospondin type 1 motif, member 13) proteolysis. $^{21}$ Furthermore, low-density lipoprotein receptor-related protein 1 (LRP1) plays a major role in shear-dependent macrophage-mediated clearance of VWF, and binds VWF exclusively under conditions of elevated shear-stress forces. ${ }^{16,17,22}$ It has been demonstrated that the VWF A1 domain contains an interactive site for LRP1 and that the degree of this site exposure is modulated by peculiar VWD2B mutations. ${ }^{23}$ Recent evidence has been provided to show that some VWD2B mutations display shear-stress independent binding to LRP1. ${ }^{23}$ Furthermore, in a mouse model macrophage-LRP1 contributes to increased clearance of R1306Q and V1316M in vivo even without shear stress, explaining the increased clearance of these type $2 \mathrm{~B}$ mutations. ${ }^{23}$

\section{Laboratory Diagnosis}

A wide heterogeneity of laboratory phenotypes is evident in VWD2B, being strictly associated with the causative mutation. The hallmark unifying all the different types of mutations, however, is the evidence of an heightened response to low concentrations of ristocetin in the RIPA assay. Usually, the laboratories screen for VWD2B by using a ristocetin concentration of $0.5 \mathrm{mg} / \mathrm{mL}$ and a response is defined as the concentration of ristocetin able to induce at least $30 \%$ of the aggregation amplitude after 3 minutes from its addition to patient's platelet rich plasma. This occurs at higher doses than $0.5 \mathrm{mg} / \mathrm{mL}$ with some mutations (e.g., P1266L) while at lower doses (even $0.3 \mathrm{mg} / \mathrm{mL}$ ) with others (V1316M). Variable reduction of plasma VWF antigen (VWF:Ag) and VWF ristocetin cofactor (VWF:RCo) is observed, but also normal levels have been reported and VWF:RCo/VWF:Ag ratio may also be normal, at variance with type $2 \mathrm{~A}$ and type $2 \mathrm{M}$. Also, FVIII may be normal or only slightly reduced. There is a tendency for fluctuating levels of both VWF:RCo and VWF:RCo/VWF:Ag ratio according to the degree of ongoing type $2 \mathrm{~B} V W F-$ platelet interaction. ${ }^{6}$ Loss of HMW and sometimes intermediatemolecular-weight multimers is typically present in patients with the mutations more frequently associated with thrombocytopenia (V1316M, R1308C) ${ }^{6}$ while the profile is normal in patients with the previously defined New York/Malmoe subtype (P1266L). 6,10,11 In keeping with the demonstrated increased binding to specific LPR1 receptors, VWF propeptide to VWF:Ag ratio is increased, ${ }^{22}$ which represents a sensitive index of increased VWF clearance. ${ }^{24,25}$

VWD2B must be distinguished from a platelet disorder expressing similar laboratory phenotype, named platelet-type VWD (PT-VWD), in which gain-of-function mutations in platelet GpIb- $\alpha$ similarly cause loss of plasma HMW VWF multimers, variable thrombocytopenia, and enhanced RIPA. ${ }^{26,27}$ Several laboratory methods have been developed to discriminate between the two disorders, including cryoprecipitate challenge and simplified RIPA mixing assays, ${ }^{27}$ but only the identification of specific mutations in GP1BA gene will clarify the different pathophysiology. ${ }^{28}$ In addition, recent evidences suggest that the bleeding tendency is milder in PT-VWD patients. ${ }^{29}$

VWD2B should be always considered in the presence of inherited chronic thrombocytopenia with large platelets on blood smear. This would also help to avoid misleading therapeutic approaches, including corticosteroids and splenectomy, as observed in the experience of the authors (G.C. and A.B., data not shown). Furthermore, in those patients with thrombocytopenia, family studies could help showing the high consistency of platelet count abnormality associated with the lifelong bleeding tendency. ${ }^{6}$

\section{Clinical Management of VWD2B: Bleeding Phenotype and Therapy}

As for the other patients with significantly low VWF, bleeding tendency in VWD2B is mainly represented by mucocutaneous bleeding. The severity and frequency of bleeding symptoms and requirement of substitutive treatment is somewhat similar to what is observed in type $2 \mathrm{~A}$ and more severe that typical type $2 \mathrm{M}$ and type 1 . From a clinical point of view, the risk of bleeding is approximately fivefold higher in VWD2B patients with associated thrombocytopenia below $140 \times 10^{3}$ platelets/ $\mu \mathrm{L}$ compared with those with normal platelet counts. ${ }^{6}$ However, wide variation again exists 
Table 3 Platelet count at baseline, platelet morphology, and median bleeding scores according to different type 2B VWD mutations

\begin{tabular}{|l|l|l|l|}
\hline Mutation & Platelet count at baseline & Platelet morphology at microscope & Median bleeding score \\
\hline P1266Q & Normal & Normal & 0.5 \\
\hline P1266L & Normal & Normal & 2 \\
\hline H1268D & Normal & Enlarged platelets & 7 \\
\hline R1306W & Low to normal & Enlarged platelets & 8 \\
\hline R1308C & Low to normal & Massive platelet clumping & 9 \\
\hline R1308L & Normal & Normal & 3 \\
\hline I1309V & Low to normal & 4 \\
\hline V1316M & Marked to slight reduction & Small platelet aggregates & 13 \\
\hline P1337L & Normal & Normal & 3 \\
\hline R1341Q & Normal & Enlarged platelets & 5 \\
\hline R1341W & Normal & Small platelet aggregates & 7 \\
\hline
\end{tabular}

Abbreviation: VWD, von Willebrand disease.

Source: Modified from Federici et al. ${ }^{6}$

according to the responsible mutation and this means that when enhanced RIPA is detected mutation detection is of utmost importance in identifying the patients more at risk of significant bleeding ( - Table $\mathbf{3}$ ). Recurrent gastrointestinal bleeding associated with gastrointestinal angiodysplasia has also been described. ${ }^{30}$ Pregnancy in VWD2B can cause or worsen thrombocytopenia and platelet transfusions have been used at parturition in some patients. ${ }^{31,32}$

VWF replacement therapy is usually required for VWD2B patients, especially in those with the mutations at risk of significant bleeding and/or thrombocytopenia. Dose and timing of administration are similar to what is usually advised in other VWD types requiring substitutive treatment. ${ }^{33}$ The goal of treatment in patients undergoing major surgery is to maintain FVIII and VWF (typically using VWF:RCo as the laboratory parameter) plasma levels around 80 to $100 \mathrm{IU} / \mathrm{dL}$ for at least a couple of days and trough level above $50 \mathrm{IU} / \mathrm{dL}$ for an additional 5 to 7 days thereafter. A loading dose of $50 \mathrm{IU} / \mathrm{kg}$ of VWF:RCo is usually given in severe cases 30 minutes to 1 hour before surgery, followed by similar daily doses for the next 2 days. A single or daily doses for 2 to 3 days of 20 to $60 \mathrm{IU} / \mathrm{kg}$ of VWF:RCo (depending on the severity of bleeding) are hemostatically effective for treating spontaneous bleeding episodes or for preventing bleeding during invasive procedures. It should be kept in mind, however, that in some situations with ongoing bleeding there could be a worsening of thrombocytopenia because of increased stimulation of the release of the abnormal VWF from endothelial cells and blood count, especially platelets, should be closely monitored.

In the past, there have been reports of possible clinical effectiveness of DDAVP in a few cases of VWD2B patients, without significant thrombocytopenia ${ }^{34}$ and there is clear evidence that some mutations (P1266L, R1308L) do not show any platelet decrease after DDAVP administration. ${ }^{6}$ However, the compound should be used cautiously and probably best avoided in patients already displaying thrombocytopenia at baseline or with mutations known to be associated with possible aggravation of thrombocytopenia.
Alloantibodies to VWF are rare and reported to occur mainly in type 3 patients in whom no VWF is synthesized in association with homozygous null mutations, including gene deletions. ${ }^{35}$ However, the occurrence of alloantibodies to VWF in a patient with VWD2B (R1308C mutation) after substitutive treatment has been recently reported. ${ }^{36}$ Interestingly, the antibody specificity seems to be restricted toward the active platelet-binding conformation of the A1 domain of $\mathrm{VWF}^{36}$ Following this report, it appears that closely monitored measurement of FVIII/VWF activities after substitutive treatment is advised, especially after intensive treatment in previously minimally treated patients.

\section{Conclusions}

VWD2B represents a rare, but fascinating bleeding disorder, which displays a wide heterogeneity of laboratory and clinical phenotypes. The interaction of type 2B VWF and platelet production and function is worthy of further studies to elucidate this complex interaction. Identifying the responsible VWD2B mutation appears relevant not only to distinguish it from the PT-VWD, but also to predict the severity of bleeding tendency and type of treatment.

\section{References}

1 Sadler JE, Budde U, Eikenboom JC, et al; Working Party on von Willebrand Disease Classification. Update on the pathophysiology and classification of von Willebrand disease: a report of the Subcommittee on von Willebrand Factor. J Thromb Haemost 2006;4(10):2103-2114

2 Ruggeri ZM. Type IIB von Willebrand disease: a paradox explains how von Willebrand factor works. J Thromb Haemost 2004;2(1):2-6

3 Ruggeri ZM, Pareti FI, Mannucci PM, Ciavarella N, Zimmerman TS. Heightened interaction between platelets and factor VIII/von Willebrand factor in a new subtype of von Willebrand's disease. N Engl J Med 1980;302(19):1047-1051

4 Ruggeri ZM, Zimmerman TS. Variant von Willebrand's disease: characterization of two subtypes by analysis of multimeric 
composition of factor VIII/von Willebrand factor in plasma and platelets. J Clin Invest 1980;65(6):1318-1325

5 Holmberg L, Nilsson IM, Borge L, Gunnarsson M, Sjörin E. Platelet aggregation induced by 1-desamino-8-D-arginine vasopressin (DDAVP) in Type IIB von Willebrand's disease. N Engl J Med 1983;309(14):816-821

6 Federici AB, Mannucci PM, Castaman G, et al. Clinical and molecular predictors of thrombocytopenia and risk of bleeding in patients with von Willebrand disease type 2B: a cohort study of 67 patients. Blood 2009;113(3):526-534

7 Randi AM, Rabinowitz I, Mancuso DJ, Mannucci PM, Sadler JE. Molecular basis of von Willebrand disease type IIB. Candidate mutations cluster in one disulfide loop between proposed platelet glycoprotein Ib binding sequences. J Clin Invest 1991;87(4): 1220-1226

8 Cooney KA, Nichols WC, Bruck ME, et al. The molecular defect in type IIB von Willebrand disease. Identification of four potential missense mutations within the putative GpIb binding domain. J Clin Invest 1991;87(4):1227-1233

9 Castaman G, Federici AB, Rodeghiero F, Mannucci PM. Von Willebrand's disease in the year 2003: towards the complete identification of gene defects for correct diagnosis and treatment. Haematologica 2003;88(1):94-108

10 Weiss HJ, Sussman II. A new von Willebrand variant (type I, New York): increased ristocetin-induced platelet aggregation and plasma von Willebrand factor containing the full range of multimers. Blood 1986;68(1):149-156

11 Holmberg L, Dent JA, Schneppenheim R, Budde U, Ware J, Ruggeri ZM. von Willebrand factor mutation enhancing interaction with platelets in patients with normal multimeric structure. J Clin Invest 1993;91(5):2169-2177

12 Nurden AT, Federici AB, Nurden P. Altered megakaryocytopoiesis in von Willebrand type 2B disease. J Thromb Haemost 2009;7 (Suppl 1):277-281

13 Jackson SC, Sinclair GD, Cloutier S, Duan Z, Rand ML, Poon MC. The Montreal platelet syndrome kindred has type 2B von Willebrand disease with the VWF V1316M mutation. Blood 2009;113(14): 3348-3351

14 Nurden P, Gobbi G, Nurden A, et al. Abnormal VWF modifies megakaryocytopoiesis: studies of platelets and megakaryocyte cultures from patients with von Willebrand disease type 2B. Blood 2010;115(13):2649-2656

15 Casari C, Du V, Wu Y-P, et al. Accelerated uptake of VWF/platelet complexes in macrophages contributes to VWD type 2B-associated thrombocytopenia. Blood 2013;122(16):2893-2902

16 van Schooten CJ, Shahbazi S, Groot E, et al. Macrophages contribute to the cellular uptake of von Willebrand factor and factor VIII in vivo. Blood 2008;112(5):1704-1712

17 Castro-Núñez L, Dienava-Verdoold I, Herczenik E, Mertens K, Meijer AB. Shear stress is required for the endocytic uptake of the factor VIII-von Willebrand factor complex by macrophages. J Thromb Haemost 2012;10(9):1929-1937

18 Castaman G. 2B or not 2B: when VWF is not a good platelet friend. Blood 2013;122(16):2772-2773

19 Casari C, Berrou E, Lebret M, et al. von Willebrand factor mutation promotes thrombocytopathy by inhibiting integrin $\alpha \operatorname{Ilb} \beta 3$. J Clin Invest 2013;123(12):5071-5081
20 Ware J. Thrombocytopathy and type 2B von Willebrand disease. J Clin Invest 2013;123(12):5004-5006

21 Hulstein JJ, de Groot PG, Silence K, Veyradier A, Fijnheer R, Lenting PJ. A novel nanobody that detects the gain-of-function phenotype of von Willebrand factor in ADAMTS13 deficiency and von Willebrand disease type 2B. Blood 2005;106(9):3035-3042

22 Wohner N, Legendre P, Casari C, Christophe OD, Lenting PJ, Denis $\mathrm{CV}$. Shear stress-independent binding of von Willebrand factortype 2B mutants p.R1306Q \& p.V1316M to LRP1 explains their increased clearance. J Thromb Haemost 2015;13(5):815-820

23 Rastegarlari G, Pegon JN, Casari C, et al. Macrophage LRP1 contributes to the clearance of von Willebrand factor. Blood 2012;119(9): 2126-2134

24 Castaman G, Tosetto A, Rodeghiero F. Reduced von Willebrand factor survival in von Willebrand disease: pathophysiologic and clinical relevance. J Thromb Haemost 2009;7(Suppl 1):71-74

25 Casari C, Lenting PJ, Wohner N, Christophe OD, Denis CV. Clearance of von Willebrand factor. J Thromb Haemost 2013;11(Suppl 1): 202-211

26 Miller JL. Platelet-type von Willebrand disease. Thromb Haemost 1996;75(6):865-869

27 Favaloro EJ. Phenotypic identification of platelet-type von Willebrand disease and its discrimination from type $2 \mathrm{~B}$ von Willebrand disease: a question of $2 \mathrm{~B}$ or not $2 \mathrm{~B}$ ? A story of nonidentical twins? Or two sides of a multidenominational or multifaceted primaryhemostasis coin?. Semin Thromb Hemost 2008;34(1):113-127

28 Othman M, Kaur H, Emsley J. Platelet-type von Willebrand disease: new insights into the molecular pathophysiology of a unique platelet defect. Semin Thromb Hemost 2013;39(6):663-673

29 Kaur H, Ozelo M, Scovil S, James PD, Othman M. Systematic analysis of bleeding phenotype in PT-VWD compared to type 2B VWD using an electronic bleeding questionnaire. Clin Appl Thromb Hemost 2014;20(8):765-771

30 Satoh Y, Kita H, Kihira K, et al. Gastrointestinal angiodysplasia in a patient with type 2 von Willebrand's disease and analysis of exon 28 of the von Willebrand factor gene. Am J Gastroenterol 2004; 99(12):2495-2498

31 Giles AR, Hoogendoorn H, Benford K. Type IIB von Willebrand's disease presenting as thrombocytopenia during pregnancy. $\mathrm{Br} \mathrm{J}$ Haematol 1987;67(3):349-353

32 Pareti FI, Federici AB, Cattaneo M, Mannucci PM. Spontaneous platelet aggregation during pregnancy in a patient with von Willebrand disease type IIB can be blocked by monoclonal antibodies to both platelet glycoproteins Ib and IIb/IIIa. Br J Haematol 1990;75(1):86-91

33 Castaman G, Goodeve A, Eikenboom J; European Group on von Willebrand Disease. Principles of care for the diagnosis and treatment of von Willebrand disease. Haematologica 2013; 98(5):667-674

34 Castaman G, Rodeghiero F. Desmopressin and type II B von Willebrand disease. Haemophilia 1996;2:73-76

35 James PD, Lillicrap D, Mannucci PM. Alloantibodies in von Willebrand disease. Blood 2013;122(5):636-640

36 Baaij M, van Galen KPM, Urbanus RT, Nigten J, Eikenboom JHC, Schutgens REG. First report of inhibitory von Willebrand factor alloantibodies in type $2 \mathrm{~B}$ von Willebrand disease. $\mathrm{Br} \mathrm{J}$ Haematol 2015;171(3):424-427 